\title{
Report on the EFSUMB 2015 Activities from President Odd Helge Gilja
}

\section{Dear EFSUMB member,}

First, I want to thank you for being an EFSUMB member, thus supporting our important mission to build a European Ultrasound Community. The last year has been very active on the ultrasound arena and there are many topics to be mentioned in the report. It is my pleasure to communicate the good news about EFSUMB activities and on plans and visions.

\section{EFSUMB's membership \\ $\nabla$}

EFSUMB's membership is stable with more than 20000 members. The federation of 28 (Sweden is back) smaller and larger societies serves the interests of all our members being the voice of EFSUMB in Europe.

\section{Benefits and costs \\ $\nabla$}

EFSUMB has reduced its costs by increasing efficiency to maximize the benefit for our members. Please, consider the benefits reported here in relation to the relatively small amount of $7 €$ EFSUMB membership fee, in short: high value for very little cost. We will have to again and again encourage all our member societies to supply the e-mail addresses of our individual members. This is a prerequisite to further drop the costs. If you have ideas on how to improve corporate identity, please, let us know your thoughts.

\section{Our EUROSON Congress}

The EUROSON congress 2015 took place in Athens, Greece. Despite serious problems in the Hellenic economy, this important multidisciplinary congress was a great success. This was made possible through the hard and dedicated work of congress president Prof Nikolas Papantoniou, his excellent committees and vice-president Prof Zoumpoulis. It was indeed a great event both regarding scientific content, educational activities, industrial contributions and social program. Congratulations Greece!!!
EFSUMB's next congress will take place in Leipzig, Germany 26-29 October 2016. I hope to see you there.

\section{EFSUMB Student Committee $\nabla$}

At the successful EUROSON congress in Athens, we discussed to include students more closely under the EFSUMB umbrella. A draft for new bylaws that will be presented at the next BoD meeting in Leipzig is made. Furthermore, we would like to establish an interim board of active students (5-10 persons) during the coming year that can start the important work. Please, do not hesitate to nominate a suitable and dedicated student from your country.

\section{EFSUMB Webinar \\ $\nabla$}

We have started a new initiative to run webinars, which is a flexible way to run seminars on various ultrasound topics. The first EFSUMB webinar was chaired by V. Cantisani from Rome and had lecturers presenting from Bad Mergentheim (C.F. Dietrich), Bologna (F. Piscaglia) and Bergen (O.H. Gilja). The theme was CEUS of the liver and the webinar was attended by at least 80 persons from all over Europe. The lectures from this webinar are available at http://ow.ly/WBjo3.

\section{Euroson Schools and Endorsed courses \\ $\nabla$}

EFSUMB has now conducted over $100 \mathrm{Eu}-$ roson Schools across Europe, thus contributing greatly to the advancement of ultrasound knowledge and skills. Last year The EFSUMB Education Committee (EPSC) approved 11 Euroson Schools and 22 endorsed courses taking place in 10 different countries, reflecting an impressive educational activity.

\section{Ultraschall in der Medizin / Euro- pean Journal of Ultrasound $\checkmark$}

The successful EFSUMB guidelines published in our official journal "Ultraschall in

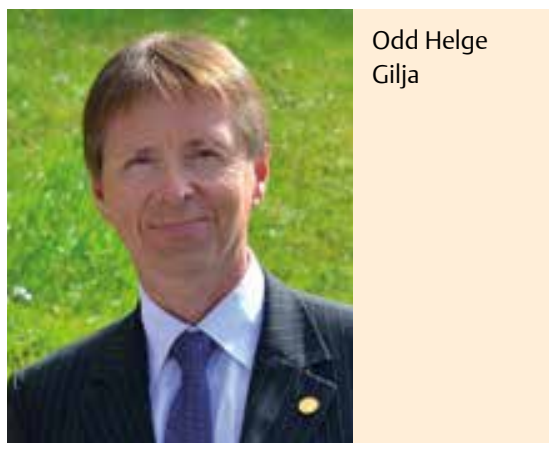

der Medizin / European Journal of Ultrasound" have gained more and more attention worldwide. The recommendations on the use of ultrasound elastography and contrast-enhanced ultrasound have been frequently cited. The impact factor (IF) of our journal has gained an impressive 4.9 which is the highest IF of an interdisciplinary ultrasound journal worldwide. I congratulate the Editors Bachmann Nielsen, Mertz, Mostbeck, Piscaglia, Seitz, Tercanli and Sidhu for their impressive results with our journal.

\section{New open access journal: Ultra- sound International Open $\nabla$}

Prof. Adrian Saftoiu, new member of EFSUMB ExB, is main editor of the new Thieme open access journal. UIO receives many articles rejected by the EJU (rejection rate of over $80 \%$ ) and invites their publication with a voucher for free publication. Caroline Ewertsen (DK) and Vito Cantisani (IT) are among the editors. The first issue was last autumn.

\section{EFSUMB guidelines and clinical re-} commendations

$\nabla$

The 6 EFSUMB guidelines on ultrasoundguided interventions have now been published. Ultrasound-guided procedures have made a great impact on everyday clinical practice in recent decades.

The guidelines consist of 6 parts:

1. Part I: General aspects of interventional ultrasound.

2. Part II: Diagnostic procedures.

3. Part III: Treatment procedures using the transcutaneous approach.

4. Part IV: Diagnostic procedures using endoscopic ultrasound.

5. Part V: Treatment procedures using endoscopic ultrasound.

6. Part VI: Vascular access. 
I am very grateful to all participants of the steering committee and working group for their substantial contributions. In particular, C.F. Dietrich deserves great honour for his leadership and tremendous energy in fulfilling this highly significant task.

An EFSUMB Task Force Group (TFG) with 20 experts from all over Europe has been set up to make new clinical recommendations and guidelines on intestinal ultrasound (IUS). The TFG is chaired by G, Maconi (Milan) and O.H. Gilja (Bergen). The first 2 guidelines will focus on IUS methodology / examination techniques and ultrasound in IBD. Four other IUS guidelines are work-in-progress: Inflammatory conditions, transrectal/perineal US, miscellaneous, and functional US. Next TFG meeting will be in conjunction with the Euroson School on IUS 21-23 April at Lake Garda.

Furthermore, EFSUMB has decided to update the guidelines on elastography. This will be done in 2 parts. The 1 . update on liver elastography will be chaired by C.F. Dietrich and the 2. update on non-liver elastography will be chaired by A. Saftoiu. Respective steering committees and working groups are now being established.

Moreover, update on non-liver CEUS guidelines is also work-in-progress under the leadership of P. Sidhu. The steering committee has been appointed and the 1 . meeting with the working group will most likely take place in London early July.

\section{EFSUMB website}

\section{$\nabla$}

The EFSUMB website including the educational portal is continuously being updated to serve our members optimally. Please, visit our website (www.efsumb.org) regularly to stay informed about latest ul- trasound news and to enjoy the vast content of educational material.

The EFSUMB Case of the Month is still the most visited webpage at our site. Due to the great efforts of the previous Editor P. Sidhu, cases have been translated in 14 languages. New case-of-the-month editor is Maija Radzina from Latvia.

\section{EFSUMB Course Book (ECB) \\ $\nabla$}

The chapters of our EFSUMB Course Book were reviewed 2014/2015 and are updated on the EFSUMB website. The printed version with colored images is still available and can be ordered at a very low price via efsumb@efsumb.org. All chapters are also free to download from our EFSUMB website.

The ECB Student Edition (ECBSE) will soon be finalized. Both projects need support from our members since they have to be updated regularly. Please, consider to review chapters and make proposals on how to improve this challenging "work in progress".

\section{EFSUMB Fellow \\ $\nabla$}

The EFSUMB BoD has created a new category of Fellow of EFSUMB to honour members who have made substantial contributions over a long period to promote the advancement or wider application of ultrasound. It was my great pleasure during the Euroson Congress in Athens to award Jan Tuma from Switzerland with this prestigious prize.

\section{Ultrasound Learning Centres (ULC) $\nabla$}

EFSUMB Ultrasound Learning Centres (ULC) are established in 7 renowned ult- rasound centres around Europe: Timisoara, Neuruppin, Cluj Napoca, Bergen, Madrid, Pavia and Zurich. At these excellent teaching sites, participants can spend a period of time to learn and to improve their knowledge in various applications of ultrasound. The teaching language is English if participants are from outside the host country. You may apply directly to the ULC Director if you like to stay for a period.

\section{Scientific Corner \\ $\nabla$}

We will continue to develop and promote research through our Scientific Corner. The interdisciplinary EFSUMB Pediatric Registry plays an important role to implement contrast-enhanced ultrasound for the benefit of our young patients. This database is now approaching 1000 cases and publications based on this very good initiative are in progress.

\section{Team spirit and friendship \\ $\nabla$}

I want to acknowledge the good team spirit we have in the EFSUMB family. A multitude of friendship is built through the important work in committees and during various conferences and courses. Particularly, I want to express my deepest gratitude to our very efficient General Secretary, Lynne Rudd, for her strong dedication to EFSUMB.

Bergen, primo January 2016

Odd Helge Gilja

EFSUMB President 2015-2017 